Case Report

\title{
Acute Systemic Viral Infection Masquerading as an Infiltrating Lymphoma in an Elderly Patient: A Case Report and Review of the Literature
}

\author{
Hani M. Babiker, ${ }^{1,2}$ Troy Wiedenbeck, ${ }^{3}$ Ryan S. Robetorye, ${ }^{4}$ Utkarsh Acharya, ${ }^{1}$ \\ Susan Wilansky, ${ }^{3}$ and Shimon Kusne ${ }^{5}$ \\ ${ }^{1}$ Division of Hematology and Oncology, The University of Arizona Cancer Center, 1515 N Campbell Avenue, Tucson, AZ 85724, USA \\ ${ }^{2}$ Division of Hospital Medicine, Mayo Clinic, 5777 E Mayo Boulevard, Phoenix, AZ 85054, USA \\ ${ }^{3}$ Division of Cardiology, Mayo Clinic, 5777 E Mayo Boulevard, Phoenix, AZ 85054, USA \\ ${ }^{4}$ Department of Laboratory Medicine and Pathology, Mayo Clinic, 5777 E Mayo Boulevard, Phoenix, AZ 85054, USA \\ ${ }^{5}$ Division of Infectious Diseases, Mayo Clinic, 5777 E Mayo Boulevard, Phoenix, AZ 85054, USA
}

Correspondence should be addressed to Hani M. Babiker; hanibabiker@email.arizona.edu

Received 12 November 2012; Revised 13 January 2013; Accepted 15 January 2013

Academic Editor: Gianfranco D. Alpini

Copyright ( 2013 Hani M. Babiker et al. This is an open access article distributed under the Creative Commons Attribution License, which permits unrestricted use, distribution, and reproduction in any medium, provided the original work is properly cited.

\begin{abstract}
Primary Epstein-Barr virus (EBV) infection occurs mainly in adolescents and young adults, with more than $90 \%$ of adults having serological evidence of past infection. Primary infection in those over the age of 40 is associated with an atypical and often more severe presentation that can lead to more extensive and invasive, and often unnecessary, diagnostic testing. The incidence of severe EBV-related illness in older adults has been observed to be increasing in industrialized nations. The characteristic presentation of infectious mononucleosis (IM) syndrome in elderly patients (age > 65) is not clearly defined in the literature. Here, we describe a case of primary EBV infection in an 80-year-old female and review the literature regarding primary seroconversion in elderly patients.
\end{abstract}

\section{Case Report}

An 80-year-old female with a history of idiopathic thrombocytopenic purpura and splenectomy presented to our institution with seven days of fevers at night, chills, night sweats, and weight loss. She lived with her husband and was independent in her activities of daily living. She was asymptomatic one week prior to initial presentation to the emergency room. Upon admission, she appeared fatigued with an exam remarkable for icterus, enlarged right neck and left supraclavicular lymph nodes (LNs), hepatomegaly, and right upper quadrant tenderness. Laboratory tests revealed a WBC of $19.7 \times 10^{9} / \mathrm{L}$ with a differential of $31 \%$ neutrophils, $58 \%$ lymphocytes, and $11 \%$ monocytes. Liver function tests (LFTs) revealed an alkaline phosphatase of $595 \mu / \mathrm{L}$, aspartate aminotransferase of $281 \mu / \mathrm{L}$, alanine aminotransferase of $200 \mu / \mathrm{L}$, and a total bilirubin of $2 \mathrm{mg} / \mathrm{dL}$. Abdominal ultrasound noted multiple enlarged porta hepatis LNs and findings suggestive of choledocholithiasis. MRCP revealed no choledocholithiasis or ductal dilatation but revealed significant interaortocaval, periportal, and common hepatic enlarged LNs. A CT scan of the chest revealed enlarged bilateral axillary and significant anterior and superior mediastinal LNs suggestive of lymphoma. An infectious disease workup was negative for viral hepatitis, mononucleosis (monospot test), coccidiomycosis, ehrlichiosis, rickettsia, QuantiFERON-TB Gold In-Tube, histoplasmosis, blastomycosis, CMV, and toxoplasmosis, and blood cultures were also negative. An excisional biopsy of a right neck LN revealed an atypical lymphoid proliferation. The surgical team initially recommended a mediastinoscopy with mediastinal LN sampling for a more adequate specimen, but a multidisciplinary group meeting concluded that ultrasound-guided needle percutaneous liver parenchyma and periportal LNs biopsies 


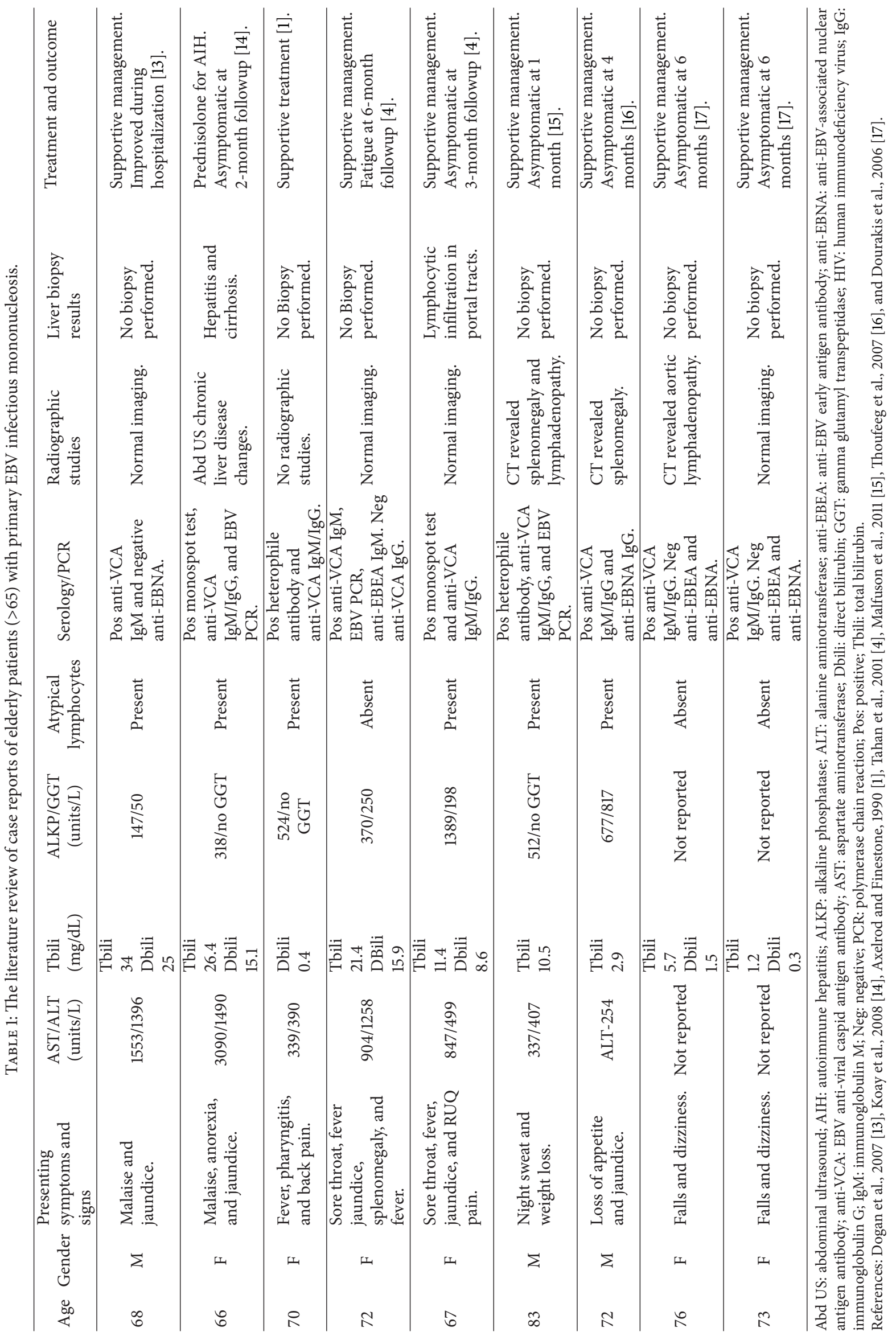




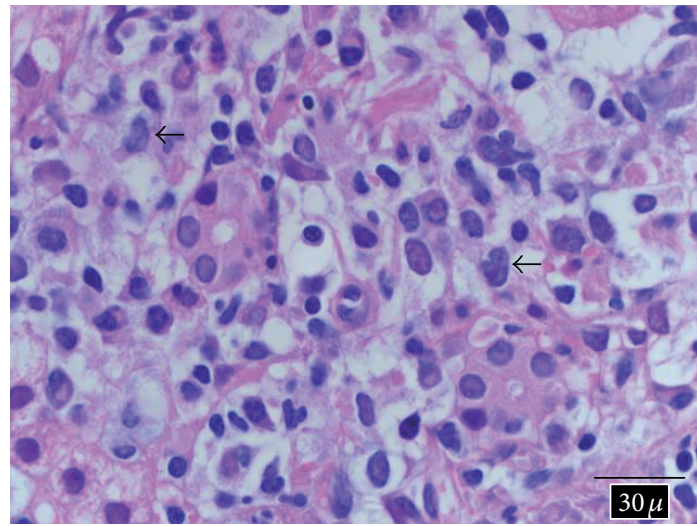

(a)

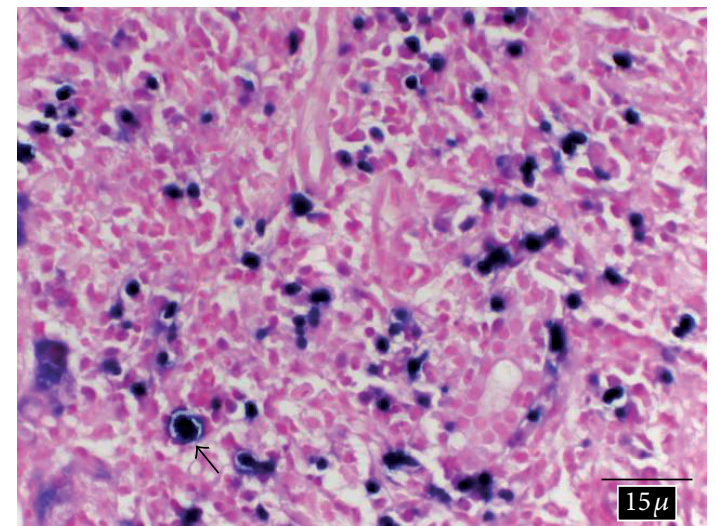

(b)

FIGURE 1: Liver biopsy: (a) high power view of H\&E-stained section of liver core biopsy showing focally prominent mixed inflammatory cell infiltrate comprised of small lymphocytes, plasma cells, neutrophils, and rare large cells with irregular nuclear contours and prominent eosinophilic nucleoli. Arrows point to large atypical lymphocytes (100x magnification). (b) EBV in situ hybridization analysis for the detection of EBV-encoded RNA (EBER) reveals abundant positive cells with dark nuclear staining, consistent with EBV infection. Arrow points to a large atypical EBV-positive cell (50x magnification).

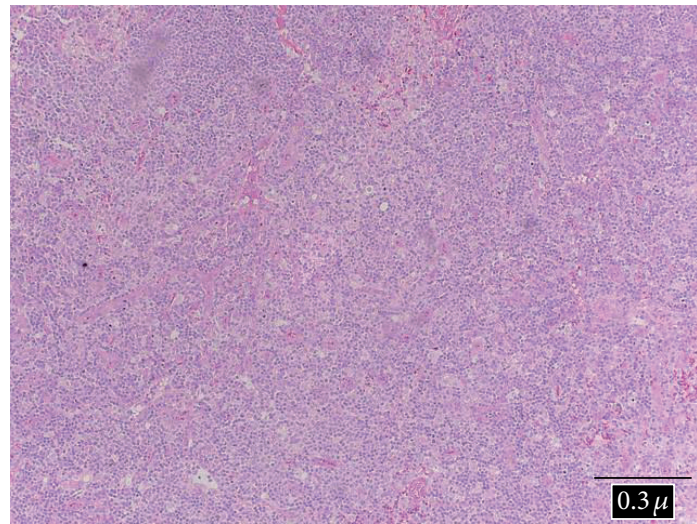

(a)

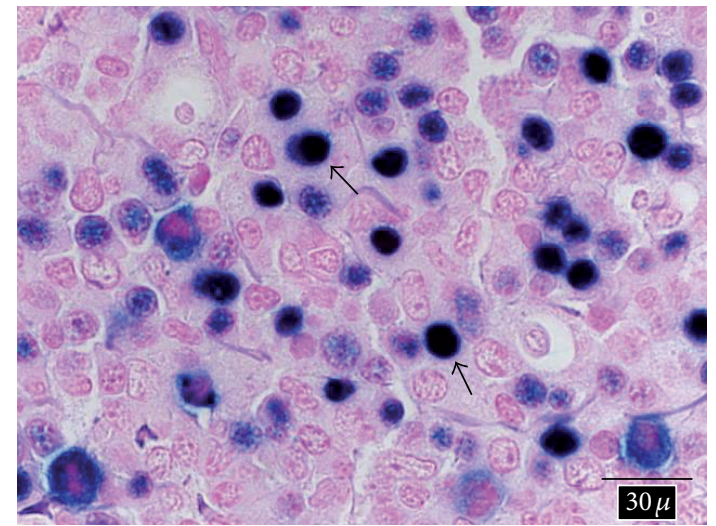

(b)

FIGURE 2: Lymph node biopsy: (a) low power view of H\&E-stained section of lymph node biopsy showing diffuse effacement of the normal lymph node architecture by a mixed infiltrate comprised of small lymphocytes, plasma cells, histiocytes, and scattered large cells with vesicular chromatin, irregular nuclear contours, and conspicuous nucleoli (10x magnification). Relatively frequent mitoses were also observed scattered throughout the specimen. (b) EBV in situ hybridization analysis for the detection of EBV-encoded RNA (EBER) reveals abundant positive cells with dark nuclear staining, consistent with EBV infection. Arrows point to large atypical EBV-positive cells (100x magnification). 
should be performed due to lower invasiveness and higher diagnostic yield potential. Liver and retroperitoneal LN core biopsies revealed an atypical lymphoid infiltrate (Figures 1(a) and 2(a)). EBV anti-EBNA and anti-VCA IgG/IgM were nonreactive; however, serum EBV DNA by PCR was elevated $(146,500$ copies/mL), suggesting acute systemic EBV infection. Furthermore, in situ hybridization analysis of the liver and LN tissue specimens was diffusely positive for EBVencoded RNA (Figures 1(b) and 2(b)), further confirming EBV as the cause of her constellation of symptoms in our seronegative patient. Immunoperoxidase stains of tissue specimen revealed an atypical lymphoid infiltrate composed of a mixed population of both B- and T-cells. A Ki-67 stain indicated that the infiltrate appeared proliferative. Flow cytometric immunophenotyping identified lymphocytes comprising $78 \%$ of total cells and consisted of a mixture of phenotypically unremarkable T-cells (66\%), polytypic B-cells (32\%), and NK cells (2\%). There did not appear to be atypical expression of CD4 and CD8 stains. The histologic and flow cytometric immunophenotyping were not diagnostic of a Bcell, T-cell, or Hodgkin's lymphoma. The patient was started on ganciclovir and subsequently switched to valganciclovir for 3 weeks on discharge. At the time of discharge (after a week of hospitalization) and during followup, the patient was asymptomatic and showed improvement in her liver function test (LFT).

\section{Discussion}

EBV is the cause of IM and is a virus of the family Herpesviridae, which consists of a linear DNA core surrounded by a nucleocapsid and an envelope that contains glycoprotein. IM occurs most commonly in younger children, with a second peak in adolescence. By adulthood, $90 \%$ of individuals have been infected and have antibody to the virus. The incidence of IM in persons over the age of 35 is two to four per 100,000 per year [1]. Young children are asymptomatic or present with mild pharyngitis, fever, fatigue, and myalgia. In contrast, elderly patients present with longer fevers, jaundice, lymphadenopathy, and hepatomegaly $[1,2]$. A study of 27 patients with IM aged 40 to 72 years revealed fever during the entire illness occurring in about $93 \%$ of elderly patients, with $37 \%$ of the patients exhibiting fevers for 14 days [3]. Approximately $52 \%$ of the patients in the study also required hospitalization. Posterior cervical, anterior cervical, and absence of lymphadenopathy occurred in $40 \%, 16 \%$, and $44 \%$ of elderly patients, respectively. Elderly patients with IM also have a higher prevalence of hyperbilirubinemia, with levels greater than $2 \mathrm{mg} / \mathrm{dL}$ occurring in $30 \%$ of patients relative to $3 \%$ in patients 35 years of age and younger [1]. The literature review of case reports of elderly patients with IM also revealed significant elevations in bilirubin and LFTs (Table 1). These findings often erroneously mislead clinicians toward a diagnosis of choledocholithiasis [3-5]. Elderly patients with IM consistently lack lymphocytosis, and the prevalence of heterophile-negative IM increases with age $[1,6-8]$. A study of elderly patients with IM revealed positive titers of anti-EBV-VCA IgM, anti-EBV-VCA IgG,
TABLE 2: Common characteristics of infectious mononucleosis in elderly patients in comparison to younger patients.

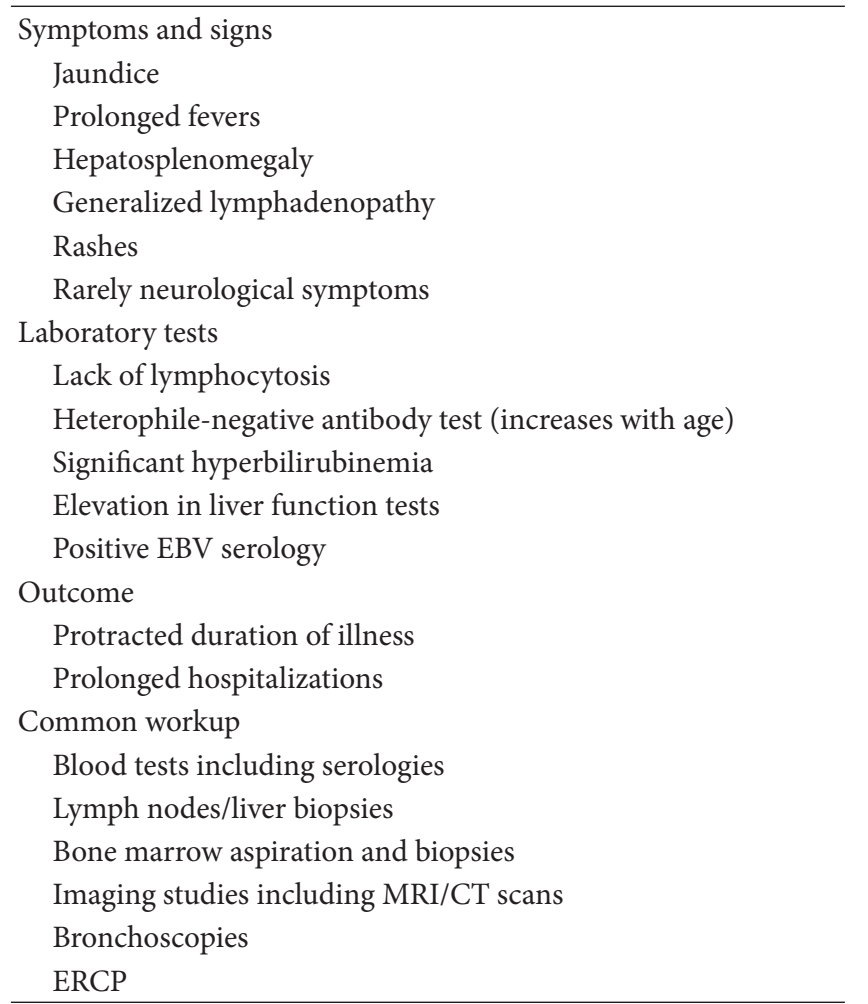

ERCP: endoscopic retrograde cholangiopancreatography. References: Horwitz et al., 1983 [3], and Axelrod and Finestone, 1990 [1].

anti-EBV EA-IgG, and anti-EBV-EBNA in 55.6\%, 88.9\%, $85.2 \%$, and $92.6 \%$ of patients, respectively [3]. In contrast to all previously published cases, our patient had negative serologies but showed significant elevation in EBV viral load. Conclusively, in comparison to younger patients with IM elderly patients tend to present with longer duration of illness with prolonged fevers, jaundice, hepatosplenomegaly, generalized lymphadenopathy, and rashes. Laboratory results frequently reveal marked hyperbilirubinemia, significant elevation in LFT, negative heterophile-antibody test, and lack of lymphocytosis (Table 2).

EBV infection is associated with the development of B-cell and T-cell non-Hodgkin lymphoma, Hodgkin lymphoma, nasopharyngeal carcinoma, and posttransplant lymphoproliferative disorders $[9,10]$. Subsets of patients also develop chronic-active EBV infection that involves progressive and recurrent IM symptoms with organ involvement and high EBV viral load over a longer period [11]. Treatment of EBV IM is usually supportive, and most cases of hepatitis resolve spontaneously. The use of steroids in acute EBV infection is controversial and should be considered only in patients with life-threatening infections. Antiviral medications and steroids reduce oropharyngeal shedding of the virus temporarily but have no clinical benefit compared to placebo [12]. Our patient was successfully treated with antiviral therapy, which resulted in prompt resolution of her presenting complaints. The literature review revealed that supportive 
care was the mainstay of treatment in elderly patients with EBV IM (Table 1). Presumptive diagnoses such as lymphoma secondary to significant lymphadenopathy, leukemia due to presence of atypical lymphocytosis, choledocholithiasis, or fever of unknown origin (FUO) can lead to delayed diagnosis and unnecessary invasive procedures. These unnecessary procedures in elderly patients with IM are due to both older age at presentation and atypical clinical presentation. Performed procedures include excisional biopsies, bone marrow aspiration and biopsies, bronchoscopies, and endoscopic retrograde cholangiopancreatography $[1,3]$. Consideration of this disease entity is essential in elderly patients with presumptive diagnoses of lymphoma, chronic lymphocytic leukemias, cholestatic jaundice, and FUO. Tests for specific EBV antibodies should be obtained, and if negative and clinical suspicion remains high, EBV viral load PCR analysis should be performed. Our case highlights the benefit of antiviral treatment for severe disease in immunocompromised elderly patients, as our patient had a recovery in one week. In addition, our study highlights the importance of a multidisciplinary approach when caring for elderly patients with unusual clinical presentations.

\section{Conflict of Interests}

The authors report no conflict of interests.

\section{References}

[1] P. Axelrod and A. J. Finestone, "Infectious mononucleosis in older adults," American Family Physician, vol. 42, no. 6, pp. 1599-1606, 1990.

[2] J. Halevy and S. Ash, "Infectious mononucleosis in hospitalized patients over forty years of age," American Journal of the Medical Sciences, vol. 295, no. 2, pp. 122-124, 1988.

[3] C. A. Horwitz, W. Henle, and G. Henle, "Infectious mononucleosis in patients aged 40 to 72 years: report of 27 cases, including 3 without heterophil-antibody responses," Medicine, vol. 62, no. 4, pp. 256-262, 1983.

[4] V. Tahan, R. Ozaras, H. Uzunismail et al., "Infectious mononucleosis presenting with severe cholestatic liver disease in the elderly," Journal of Clinical Gastroenterology, vol. 33, no. 1, pp. 88-89, 2001.

[5] Y. Edoute, Y. Baruch, J. Lachter, E. Furman, L. Bassan, and N. Assy, "Case report: severe cholestatic jaundice induced by Epstein-Barr virus infection in the elderly," Journal of Gastroenterology and Hepatology, vol. 13, no. 8, pp. 821-824, 1998.

[6] K. E. Schmader, C. M. van der Horst, and M. E. Klotman, "Epstein-Barr virus and the elderly host," Reviews of Infectious Diseases, vol. 11, no. 1, pp. 64-73, 1989.

[7] A. Hornsleth, J. Siggaard-Andersen, and L. Hjort, "Epidemiology of herpesvirus and respiratory virus infections-part 1. Serologic findings," Geriatrics, vol. 30, no. 8, pp. 61-68, 1975.

[8] C. A. Horwitz, W. Henle, and G. Henle, "Heterophil-negative infectious mononucleosis and mononucleosis-like illnesses. Laboratory confirmation of 43 cases," American Journal of Medicine, vol. 63, no. 6, pp. 947-957, 1977.
[9] O. A. Odumade, K. A. Hogquist, and H. H. Balfour Jr., "Progress and problems in understanding and managing primary epsteinbarr virus infections," Clinical Microbiology Reviews, vol. 24, no. 1, pp. 193-209, 2011.

[10] M. J. Goldacre, C. J. Wotton, and D. G. R. Yeates, "Associations between infectious mononucleosis and cancer: record-linkage studies," Epidemiology and Infection, vol. 137, no. 5, pp. 672-680, 2009.

[11] M. Okano, K. Kawa, H. Kimura et al., "Proposed guidelines for diagnosing chronic active Epstein-Barr virus infection," American Journal of Hematology, vol. 80, no. 1, pp. 64-69, 2005.

[12] D. Torre and R. Tambini, "Acyclovir for treatment of infectious mononucleosis: a meta-analysis," Scandinavian Journal of Infectious Diseases, vol. 31, no. 6, pp. 543-547, 1999.

[13] I. Dogan, M. Ergun, M. Cindoruk et al., "Acute hepatitis induced by Epstein-Barr virus infection: a case repot," Turkish Journal of Gastroenterology, vol. 18, no. 2, pp. 119-121, 2007.

[14] L. B. Koay, S. L. Tsai, C. S. Sun et al., "Chronic autoimmune hepatitis with Epstein-Barr virus superinfection: a case report and review of literature," Hepatogastroentrology, vol. 55, no. 8687, pp. 1781-1784, 2008.

[15] J. V. Malfuson, F. Dutasta, J. Konopacki et al., "Infectious mononucleosis and monoclonal B lymphocytosis in an elderly man," Journal of American Geriatric Society, vol. 59, no. 11, pp. 2156-2157, 2011.

[16] M. H. Thoufeeg, S. L. Ali Khan, S. K. Jain et al., "A case of acute infectious mononucleosis presenting with very high ferritin," World Journal of Gastroenterology, vol. 13, no. 4, pp. 637-638, 2007.

[17] S. P. Dourakis, A. Alexopoulou, N. Stamoulis et al., "Acute Epstein-Barr virus infection in two elderly individuals," Age Ageing, vol. 35, no. 2, pp. 196-198, 2006. 


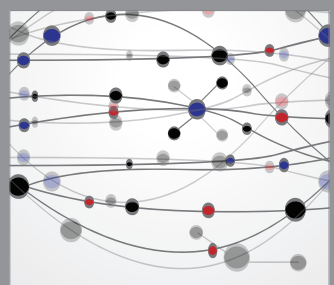

The Scientific World Journal
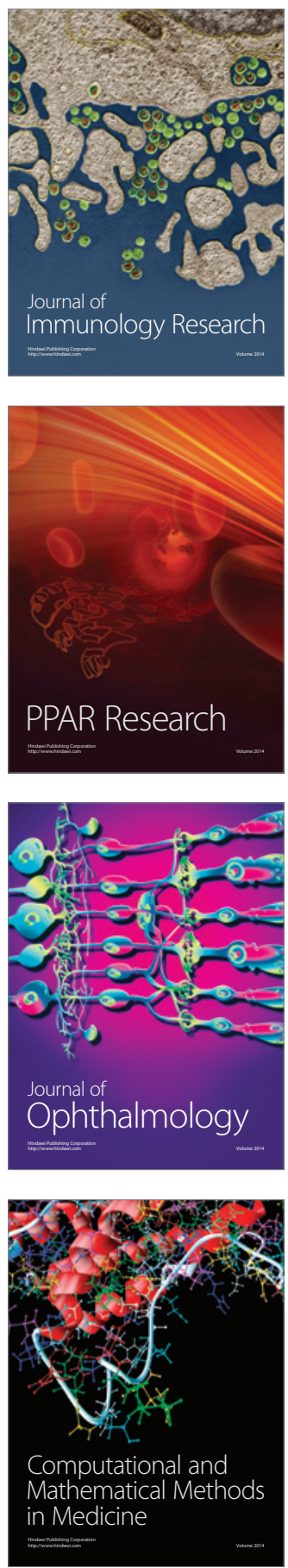

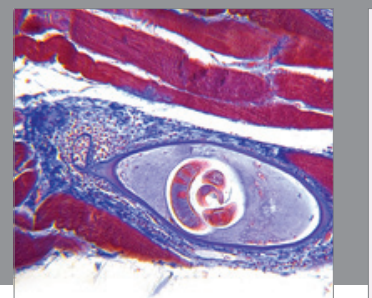

Gastroenterology

Research and Practice
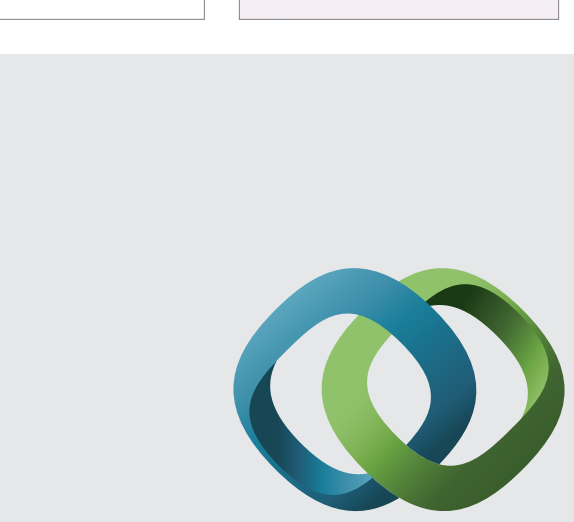

\section{Hindawi}

Submit your manuscripts at

http://www.hindawi.com
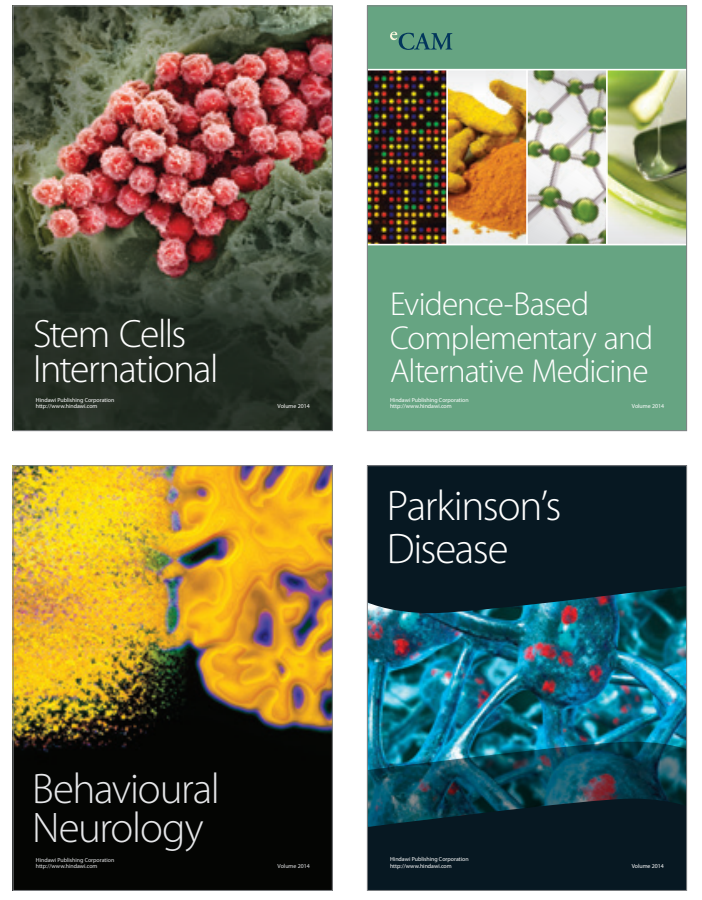
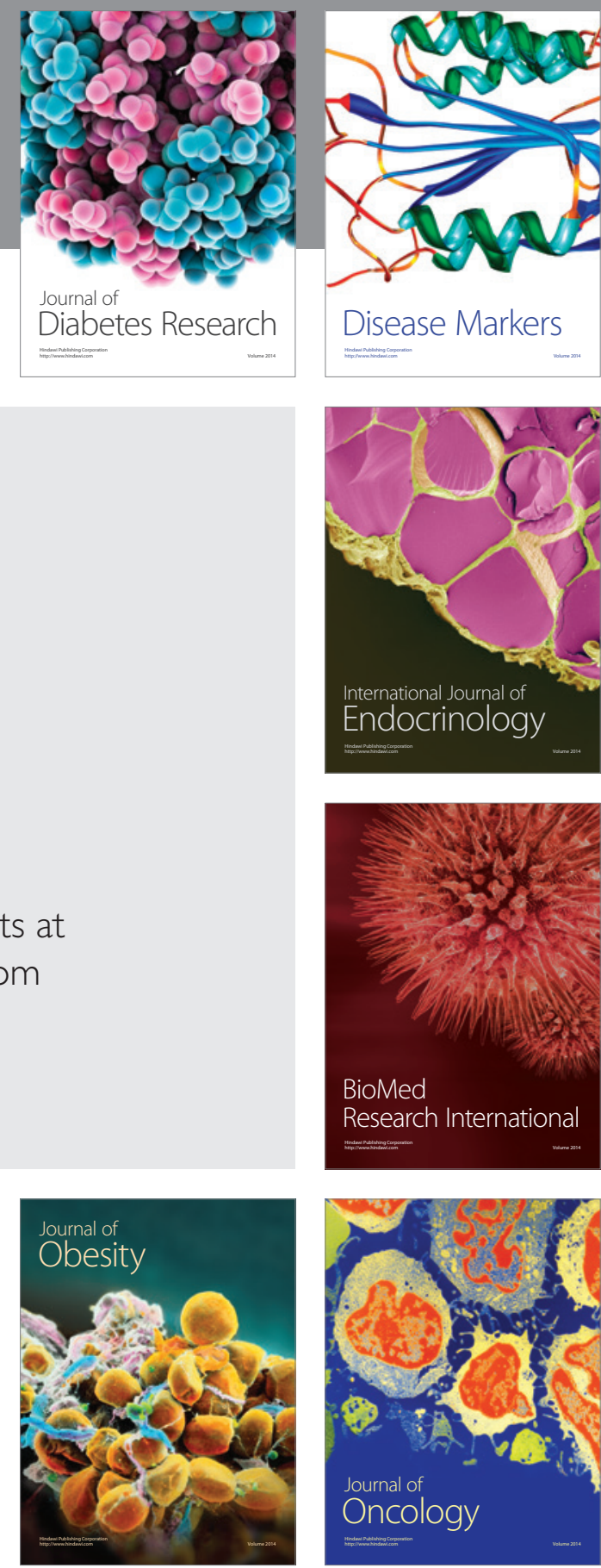

Disease Markers
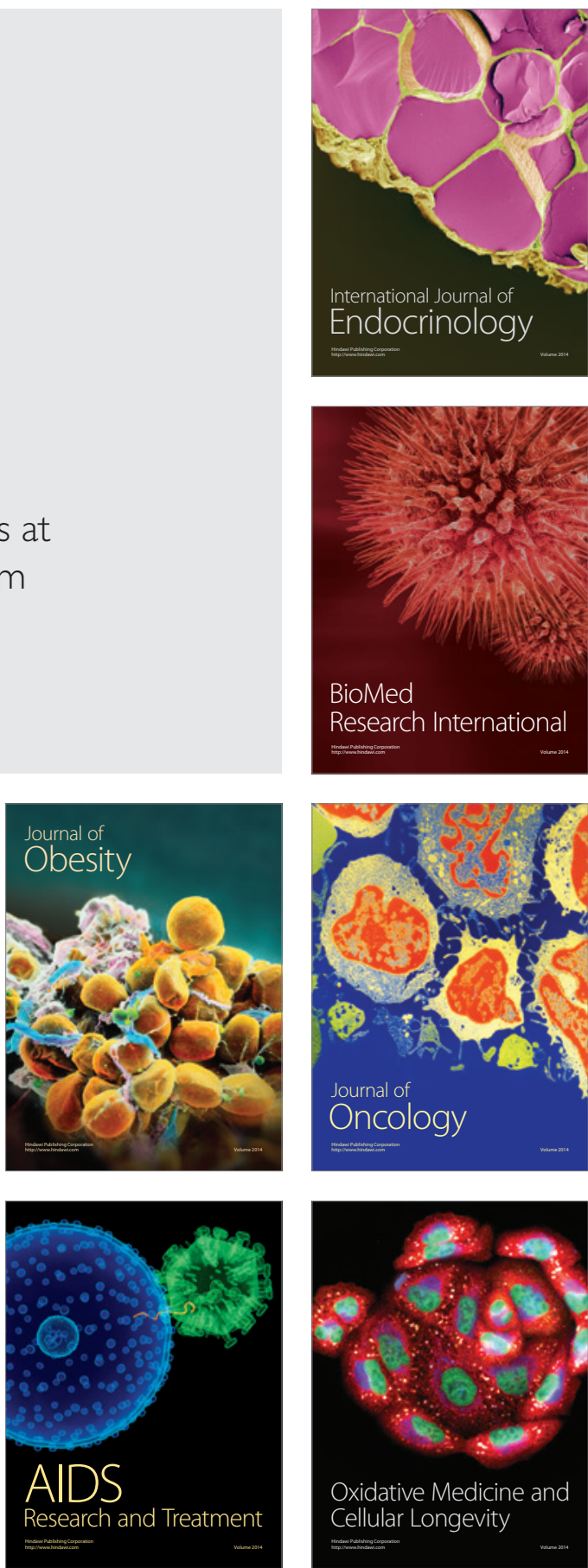